\title{
LIBRARY MECHANIZATION AT AUBURN COMMUNITY COLLEGE
}

Eloise F. HILBERT: Head Librarian, Auburn Community College, Auburn, New York

Use of an IBM 1401 computer and a single keypunch operation for changing a college book collection from Dewey decimal to Library of Congress classification; for acquisitions, accounting and circulation procedures; and for production of a list of periodical holdings. A mark-sense reproducer is used for the circulation system.

\section{INTRODUCTION}

Auburn Community College, a two-year college and one of the fifty-two units of the State University of New York, was founded in 1953 as one of the first community colleges in the state. Like other institutions of higher learning, it has experienced a rapid growth. There are about 1500 students enrolled in the day division and about 1500 in the evening division. The college offers courses in data processing in addition to the usual curriculum offerings. The library possesses approximately 40,000 volumes and adds about 3,000 volumes a year.

The Librarian attended a one-week IBM customer executive conference for librarians on the subject of automation in Endicott, N.Y. in April 1967, and returned eager to consider ways of applying computer technology to some of the Library's procedures. Data processing equipment, located directly beneath the Library, was available for Library use. The limited Library staff, both professional and clerical, would benefit by automating of technical processes, since automation would eliminate much typing and reduce tedious tasks. Clerical staff would have time to take over clerical operations that were being performed by professional staff, freeing the latter for more professional work. 
Upon approval by the college administration of plans for automating, discussions took place between the librarians involved and the Chairman of the Data Processing Department. There was considerable interest and cooperation among the Library staff and Data Center personnel. Library literature describing computerization in academic libraries was reviewed, but there was a decided lack of information available concerning automation of libraries approximately the same size as Auburn's. A proposed use of mark-sense cards in the circulation system also appeared to be unique. IBM publications on library applications served as guides in developing the systems $(1,2,3)$. Decisions were made to automate a projected reclassification, the acquisitions and circulation systems and accounting procedures, and to produce lists of the serial holdings (4).

The IBM Processing installation used for the Library comprised the following: 1401 computer, 12K storage; 1402 Card Reader Punch; 1403 Printer; 1311 disk storage drive; 514 mark-sense reproducer; 083 sorter; 548 Interpreter; 026 keypunch.

\section{RECLASSIFICATION}

A decision had previously been made to change the classification of the Library's collection of 30,000 books from the Dewey decimal to the Library of Congress system. Since the tedious task of erasing or painting over and retyping catalog card numbers and entries, book pockets and book cards would be greatly reduced by automation, it was decided that reclassification of the book collection should be the first automated procedure.

The aim was to complete conversion as quickly as possible in order to avoid confusion in the Library. The Data Center made its staff available for the summer months so that much of the conversion was completed at that time.

Conversion of the shelf list presently in Dewey decimal classification was to be the key step. The shelf list was sent to the Data Center, where one IBM shelf list card was punched for each volume. Accession number, call number, author's name and title, copyright date, and publisher were carefully abbreviated to fit into six fixed fields of the eighty columns on the card. These fields would appear repeatedly in later processes so this bibliographic record, which would be used in later procedures, needed to be keypunched only once.

Keypunch operators were instructed to use the Library of Congress number on the catalog card instead of punching the Dewey decimal number. All cards that did not have complete Library of Congress cataloging were returned from the Data Center to the Library for necessary additions and corrections. The decision was made to accept the Library of Congress classification call number exactly as it appeared on the card, in order to keep original cataloging to a minimum.

This abbreviated shelf list punch card was sufficient for the purpose 


\section{Journal of Library Automation Vol. 3/1 March, 1970}

presently planned for its use. It was considered unnecessary to provide complete bibliographical detail, which would be available from the main card catalog. Punched shelf list cards would produce accession lists, "new book" lists, and bibliographies of books in abbreviated form. There was no interest in producing catalog cards, which would have required much more work and more time than was available.

Once the shelf list cards had been punched, reclassification proceeded as follows: the punched shelf list card was used as the source card to create the circulation book card, duplicating accession number, call number, author and title. The punched shelf list card also produced the gummed labels, a label for the book pocket, the spine label, and labels for the catalog cards. The punched cards had been produced in Dewey decimal order from the catalog trays. Labels, shelf list and circulation cards were placed with the Dewey decimal shelf list card to make a set. It was important to keep them in Dewey decimal order, since the books would come off the shelves in that order.

Each set of labels and cards was placed in its respective book, labels were attached to the book pockets already in the books, and call number labels were applied to the spines of the books. The remaining labels were filed with the Dewey shelf list card and later attached to the other cards in the card catalog. Circulation cards were inserted in the book pockets and the books were returned to the stacks, which had been relabeled with Library of Congress numbers. Student assistants were used to perform this work under the supervision of the librarians. Originally, it was estimated that the job would require three years, but by automated procedures reclassification took only about six months.

Attaching the labels to the cards in the card catalog did take another year. Labels were placed on the cards at the card catalog without removing cards from the trays. Instruction was given and examples were displayed to show how to locate the new Library of Congress number on the catalog card, thus the use of the card catalog was not hindered by the lack of labels on the cards. This method seemed to be the most efficient, since new cards would have been expensive, headings would have had to be retyped and all cards refiled again.

\section{CIRCULATION (Figure 1)}

A machine readable shelf list made possible an automated circulation system, since producing a machine readable circulation card (Figure 2) would be a simple computer operation. The old circulation system presented the usual problems but manually preparing the over-dues was costly and time consuming and would benefit most from automation.

Total circulation for the Library for $1968 / 69$ was 18,000 books. The maximum number of books charged out per day was one hundred and fifty books and the minimum, twenty-five. Maximum size of the loan record file was about two thousand charges. 
Library Mechanization at Auburn/HILBERT 15

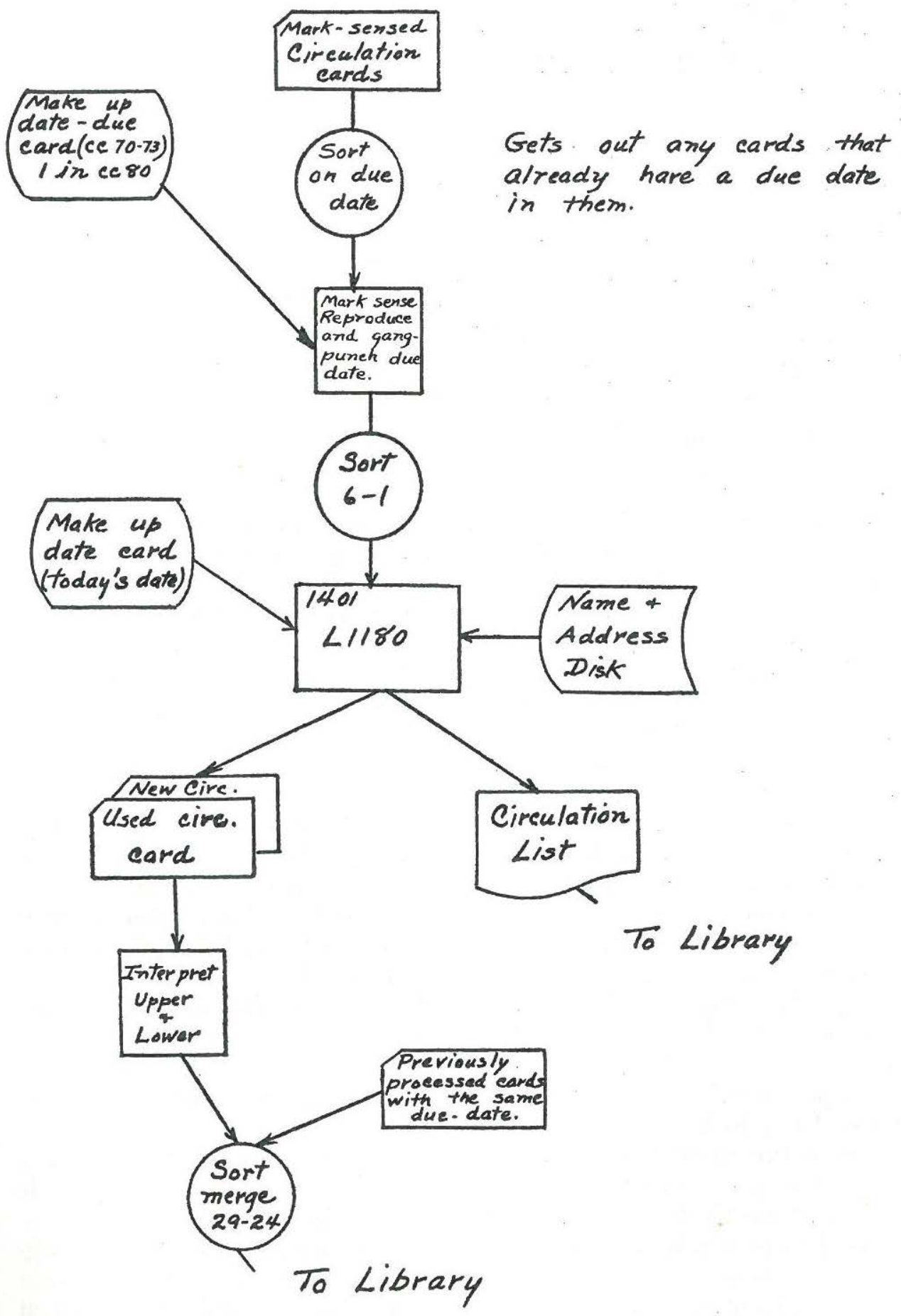

Fig. 1. Circulation Flow Chart. 


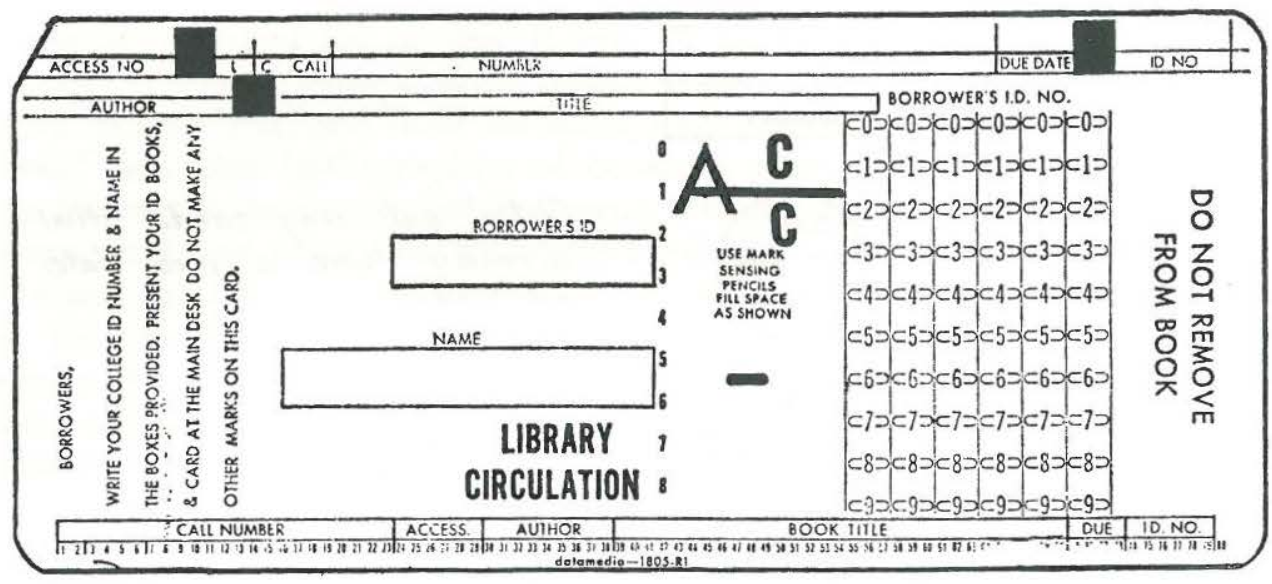

Fig. 2. Circulation Card.

A mark-sense reproducer prepares the cards for the computer. This reproducer had been acquired for other college computer functions and the Library was able to make use of it (2). Under this plan the books are charged out by having the borrower write in his identification number, which serves as the borrower's number, and his name in the appropriate box on the IBM circulation card (3). The student assistant at the desk mark-senses the book card with the identification number; this is the one manual operation, but it has presented no problem. The marked circulation cards are sent three times a week to the Data Center, where the mark-senses are read and punched and the due date is gang-punched in.

The 1401 computer generates a second circulation card, duplicating the accession number, call number, author and title. Old and new circulation cards are machine filed together by accession number and returned to the circulation file, which is arranged by date and accession number. It was found that the accession number is easier to read than the Library of Congress number and is the truly unique number.

A printed circulation listing, arranged by call number to facilitate use, is kept at the charge desk; it shows accession number, author and title, borrower's name, identification number and due date. It is also possible to prepare a daily circulation report by student identification number and name if required.

The entire circulation is sent to the Data Center weekly to produce a cumulative print-out of all books in circulation. These print-outs provide daily and weekly totals of all outstanding circulated books.

No data processing equipment is required for reserve circulation. Charging out of books on reserve continues to be done by having the borrower write his identification and name on a blue reserve card to be kept at the desk. 
When a book is returned, the pair of circulation cards are selected from the circulation file. The used charge card, which contains the borrower's identification number and due date, is marked "cancelled" with a rubber stamp. The new circulation card is inserted in the pocket of the book and the book is reshelved. Cancelled circulation cards are kept and sorted later to provide statistical analyses by date and class number for each semester. This system was developed because it was felt a small library could not justify expensive charging machinery.

\section{ACQUISITIONS AND SHELF LIST}

Once the reclassification operation was organized it was possible to set up automation procedures for processing current acquisitions. An IBM card was designed as a book request card (Figure 3) to be filled in by staff or faculty member. Information on it includes author's name, title, publisher, price purchase order number, academic department, and requestor's name. At the Data Center the foregoing information is keypunched into the card, which then becomes a purchase order card. The purchase order number identifies the vendor and is gang-punched into the cards. A computer print-out produced from the purchase order cards is mailed directly to the dealer as a book order. Order cards are kept in an "on order" file by dealer or purchase order number and then by author until the books are received.

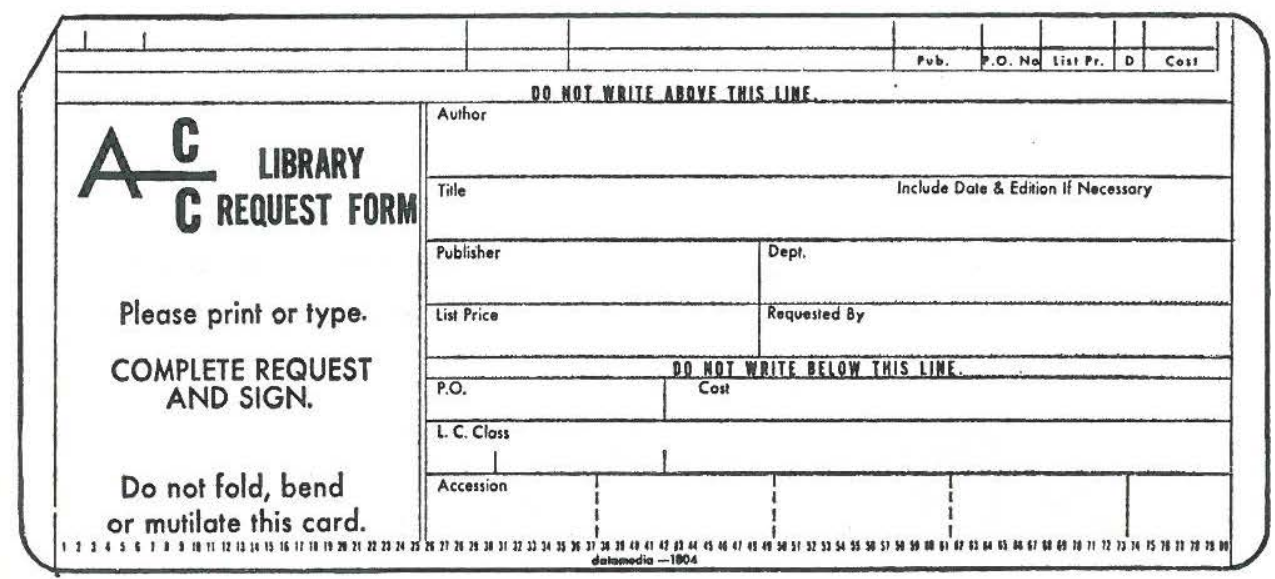

Fig. 3. Book Request Card.

When the book and its Library of Congress cards have been received, the corresponding order cards are pulled and the following additional information is added to the purchase order card: actual cost (taken from the invoice), accession number (stamped on), and the Library of Congress call number (taken from the Library of Congress printed card). Figure 4 is a flowchart of the acquisitions procedure. The books are then processed in the same manner as was used for reclassifying (1). 
18 Journal of Library Automation Vol. 3/1 March, 1970

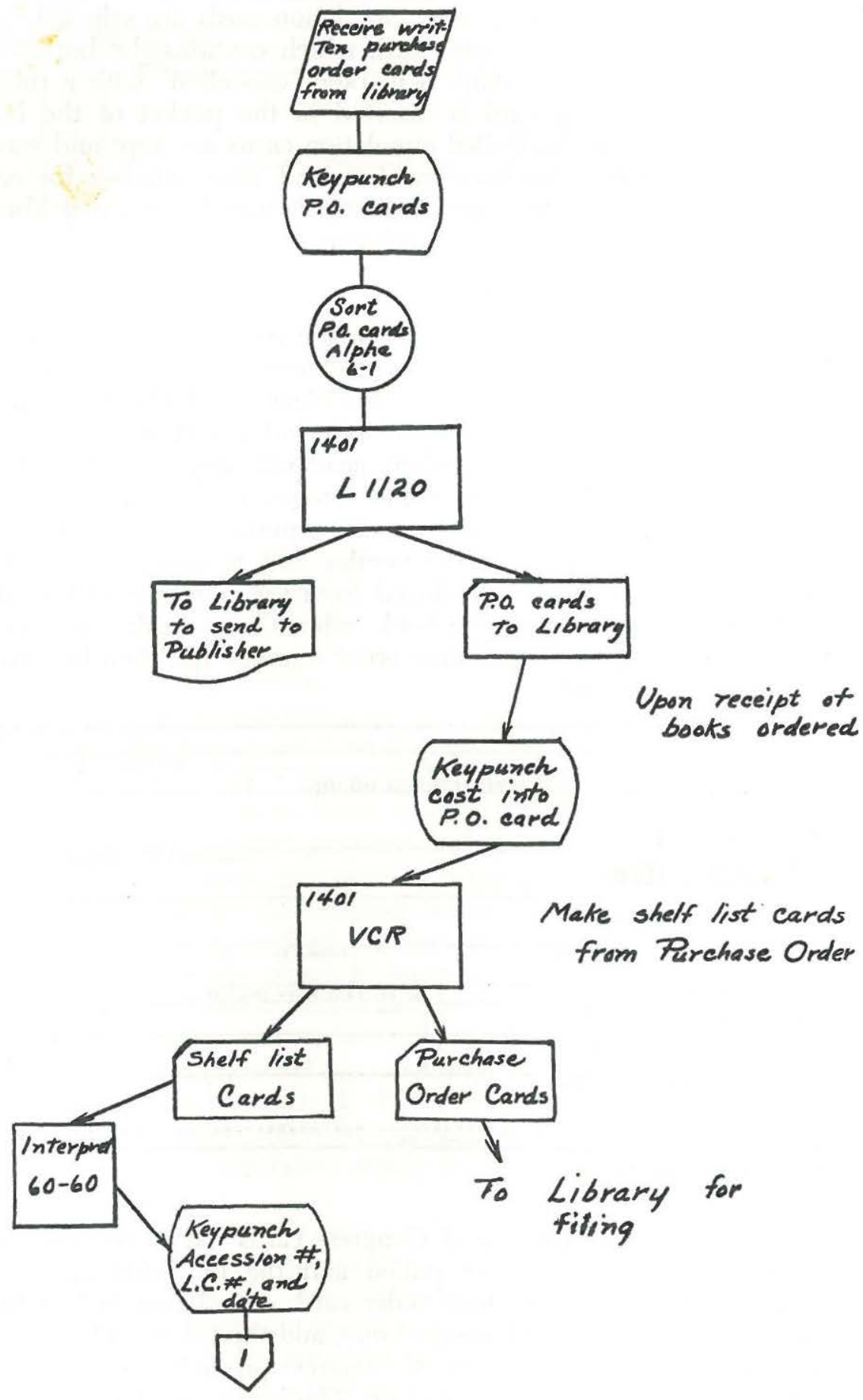

Fig. 4. Acquisitions Flow Chart. 


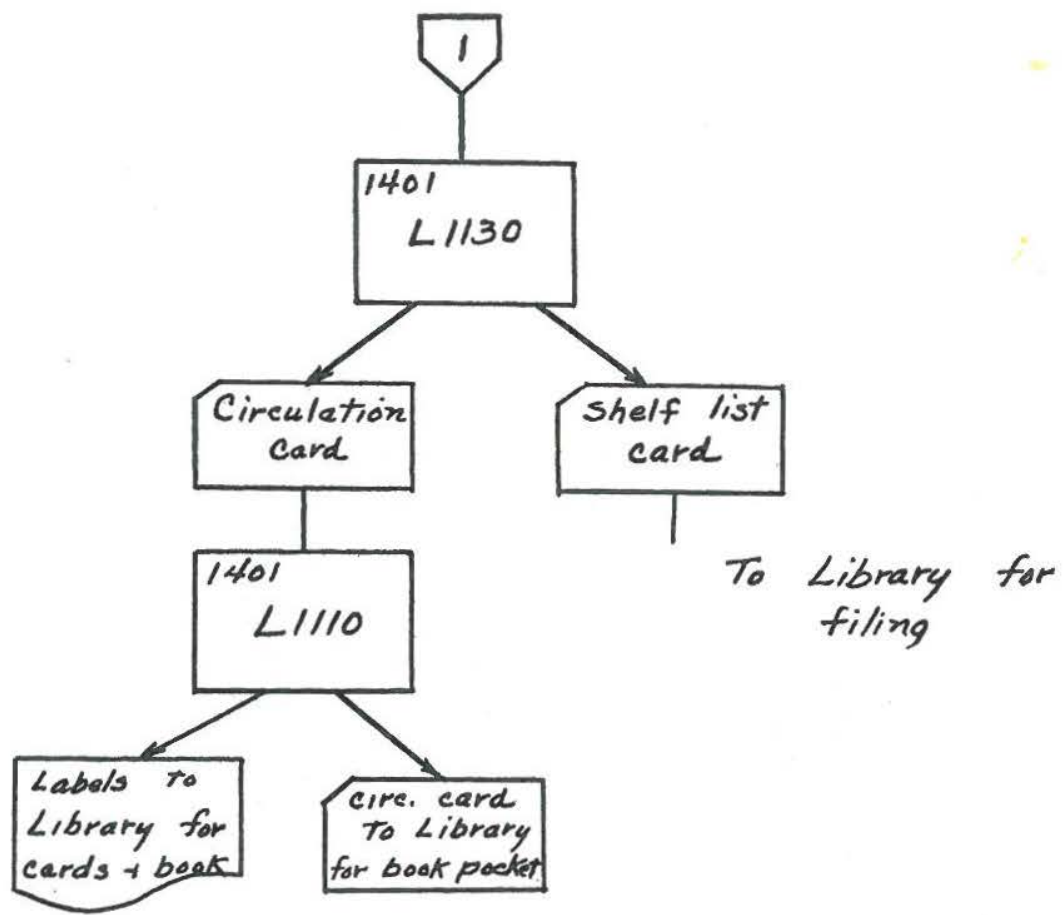

Fig. 4 continued.

Order cards are sent to the Data Center to reproduce the shelf list cards, automatically transferring the pertinent information already punched in the order card and keypunching the additional information into the shelf list cards (Figure 5). Currently, provision is being made for inclusion of the Library of Congress card order number in the shelf list card to enable easy subsequent selection of the corresponding MARC records.

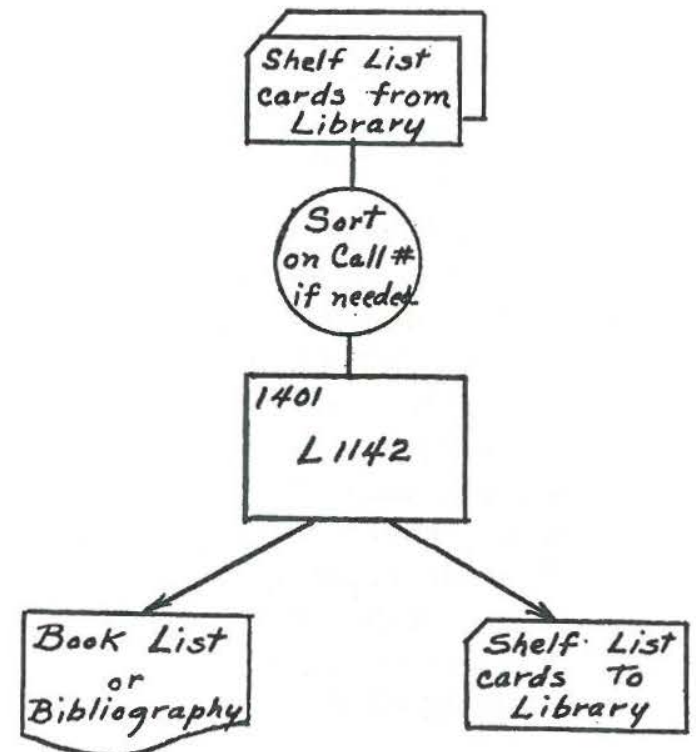

Fig. 5. New Books Listing Procedure. 
The shelf list cards are used to produce the new books list (Figure 5). The shelf list is kept in the IBM card form, and a book catalog could easily be made if so desired. To compile a bibliography it is only necessary to take the punched cards from the shelf list in the wanted classification. The Library's subject catalog and the Library of Congress subject headings are checked to determine the class numbers to be used. As depicted in the flowchart in Figure 5, these cards are put through the computer to produce the print-out, and then returned to the punched shelf list file.

This system was designed to produce a bibliographical record of the books in the library and to automate the technical processing of the books in as simple a method as possible so as not to defeat the purpose of automating.

\section{ACCOUNTING (Figure 6)}

The accounting system was designed to use the book request card after it has had department and cost punched into it. After the books are processed, accumulated request cards are sent periodically to the Data Center, where computer print-out is produced by department, listing the books purchased and the cost of each, with a summary showing all expenditures. Copies are sent to department chairmen to keep them informed of their expenditures. These order cards are kept for a semester, then returned to the individual requesting faculty members after a cumulative accounting record has been made. By this means it is possible to keep track of each department's book budget and the Library's total book budget, with the computer doing all the work.

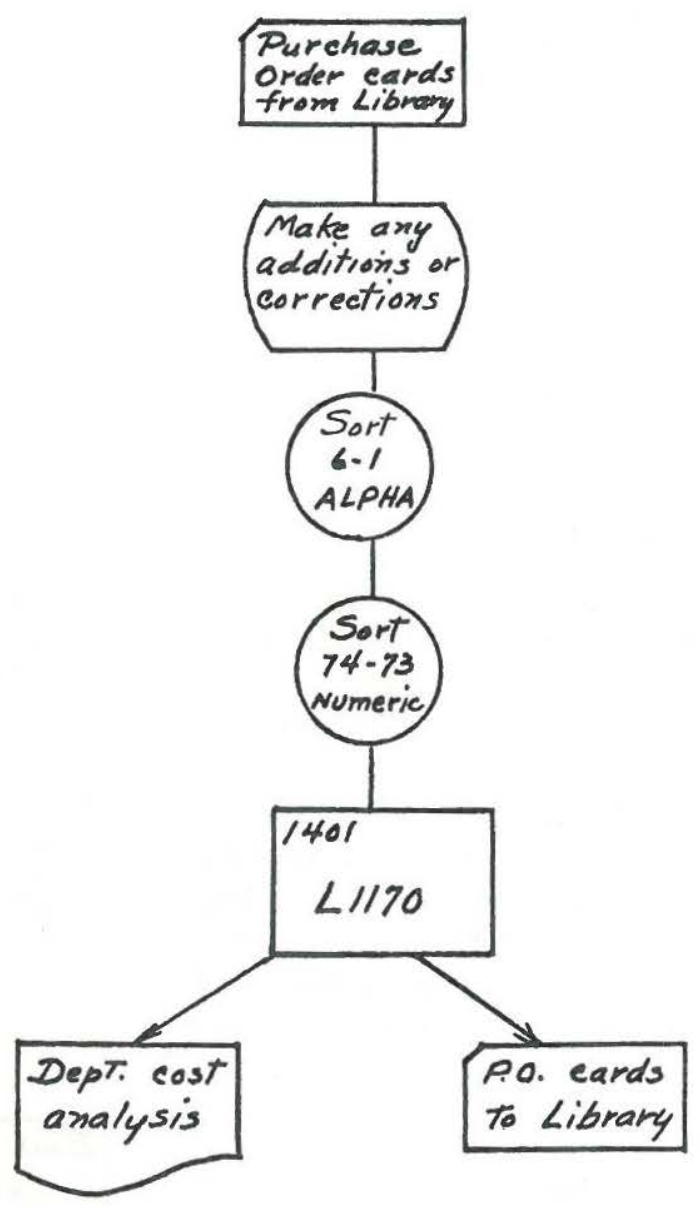

Fig. 6. Accounting Procedure. 


\section{OVERDUES (Figure 7)}

Overdue notices are machine prepared from overdue circulation cards which are selected periodically from the charge-out file. The cards are passed through the computer, which generates second and third overdue

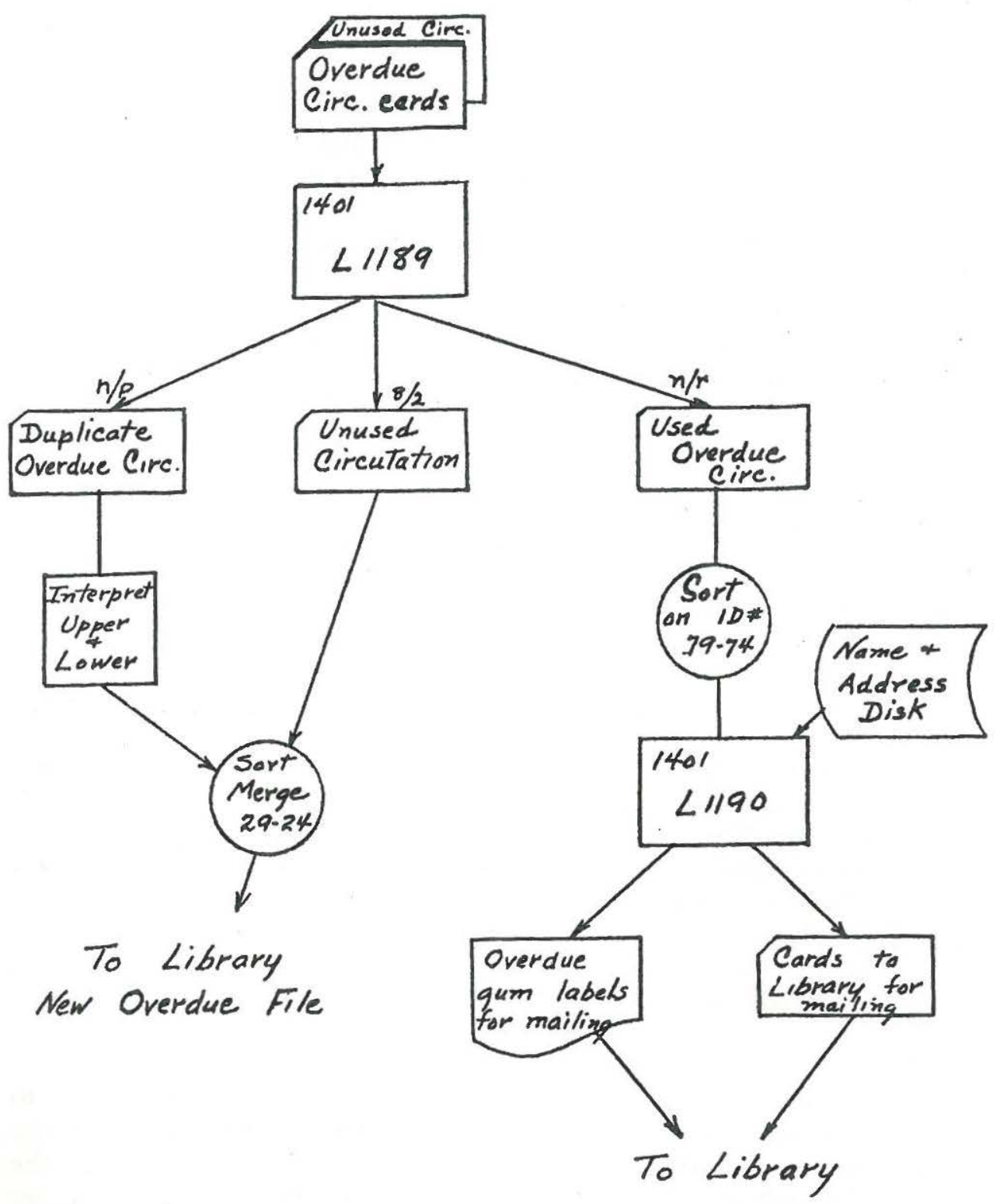

Fig. 7. Overdue Procedure. 
cards to be used for discharging purposes. Gummed address labels that include the student identification number are produced using the college log of names and addresses. The appropriate label is applied to the reverse side of the circulation card using the I.D. as a guide. Each notice card is stamped "Overdue book, please return as soon as possible," then sent through the postage meter and placed directly in the mail. If several overdues are sent to the same person, the cards are mailed in an envelope, using the gummed label. The second and third notice cards are filed at the circulation desk until needed or until the book is returned.

There is another file for borrowers who are seriously delinquent in returning their books. Cards that have accumulated in this overdue file are processed as follows to generate further overdue notices: an overdue notice is sent to the borrower, the Dean's letter to the borrower or to his parents, and the list of names to the Dean and the student personnel office.

At the end of each semester a list is prepared indicating all books held by individual faculty members for more than three months and the latter are notified. The time-consuming operation of preparing overdues has been considerably reduced (4).

\section{SERIALS}

Serial holdings have been converted to machine readable punched cards. The State University of New York, under the direction of Dr. Irwin Pizer of the Upstate Medical Center at Syracuse, has recently published a union list containing the titles of all periodicals received in all units of the State University (5). It includes the serial holdings of Auburn Community College, (approximately 400 titles) and punched cards for these holdings are used by the Library adapted for its use. Information on the card comprises title, inclusive dates, years on microfilm, department for which the periodical was ordered and the indexes in which the periodical is listed. Each new serial title added to the holdings is keypunched with this information. The punched cards are used to print out an alphabetically arranged title listing and a departmental listing. Adding or withdrawing titles is a simple matter, and up-to-date lists of periodical holdings are easily produced by the computer. Copies of the lists are sent to each faculty member and several copies are available at the desk and in the periodical room.

\section{COSTS}

Since Library use of the Data Center was considered to be similar to other college uses (e.g., that of the Business Office), the cost of library automation was absorbed by the Data Center and not charged to the Library. An estimate of the cost, including rental time on the computer (about three hours per week), supplies, and Data Center staff time, is about $\$ 1500.00$ a year for ongoing programs. 


\section{CONCLUSION}

The automated systems herein described have now been completely operational for over a year. Converting data for a computer operation spotlighted inaccurate recording of information and afforded a good opportunity for correcting previous errors. Periodically, progress and results have been reviewed and changes made, as will continue to be the case. The automated circulation system is providing the library with rapid, accurate, and efficient circulation control not possible for a manual system. Ease and speed of performing routine library operations by the use of automation more than compensates for the cost of data processing. Automated technical procedures provide for faster and more efficient processing of books, production of the Library's monthly new books list (which previously took hours to type) and subject bibliographies. Other important results of the mechanization project are the serial listings and departmental accounts, all of which make possible better library service.

\section{ACKNOWLEDGMENTS}

The programming was done in AUTOCODER by, or under the supervision of, Mr. Richard Klinger, Chairman of the Data Processing Department at Auburn Community College; to him is due most of the credit for the mechanization of the Library. The Library is grateful to Mr. Klinger for his encouragement and enthusiastic support and his willingness to assume the technical responsibilities of programming and systems design.

\section{REFERENCES}

1. International Business Machines: Mechanized Library Procedures. (White Plains, N. Y.: IBM, n. d.).

2. International Business Machines: Library Processing for the Albuquerque Public School System (White Plains, N. Y.: IBM, n. d.).

3. DeJarnett, L. R.: "Library Circulation." In International Business Machines Corporation: IBM Library Mechanization Symposium (Endicott, N. Y.: 1964), pp. 78-93.

4. Eyman, Eleanor G.: "Periodicals Automation at Miami-Dade Junior College," Library Resources and Technical Services, 10 (Summer, 1966), 341-61.

5. The Union List of Serials in the Libraries of the State University of New York. (Syracuse, N.Y.: State University of New York Upstate Medical Center, 1966). 